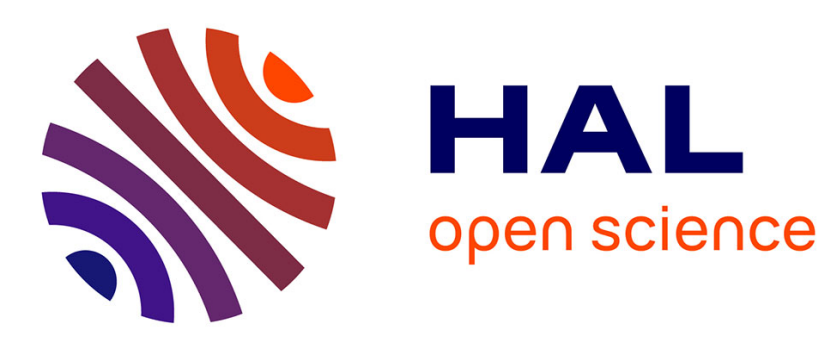

\title{
Climate change tweaks Arctic marine ecosystems
}

Marcel Babin

\section{To cite this version:}

Marcel Babin. Climate change tweaks Arctic marine ecosystems. Science, 2020, 369 (6500), pp.137138. 10.1126/science.abd1231 . hal-03094693

\section{HAL Id: hal-03094693 https://hal.science/hal-03094693}

Submitted on 5 Jan 2021

HAL is a multi-disciplinary open access archive for the deposit and dissemination of scientific research documents, whether they are published or not. The documents may come from teaching and research institutions in France or abroad, or from public or private research centers.
L'archive ouverte pluridisciplinaire HAL, est destinée au dépôt et à la diffusion de documents scientifiques de niveau recherche, publiés ou non, émanant des établissements d'enseignement et de recherche français ou étrangers, des laboratoires publics ou privés. 


\title{
Title: De-icing Arctic marine ecosystems
}

\author{
Authors: Babin, Marcel $^{1 *}$.
}

\section{Affiliations:}

${ }^{1}$ Takuvik International Research Laboratory (Université Laval and CNRS), Université Laval, Quebec City, Qc, G1V 0A6, Canada

*Correspondence to: marcel.babin@takuvik.ulaval.ca.

\section{Main Text:}

The thinning and shrinking of the icepack bring to light the fairly dark Arctic Ocean (OA), stimulating micro-algae biomass buildup, and promoting the productivity of the marine ecosystem. This seemingly reasonable assertion is in fact a matter of lively debate centered on the fundamental functioning of the Arctic marine ecosystem and its fate under climate change pressure. The opposite paradigm indeed postulates a stagnant AO chronically short on nitrogen, an inorganic element essential to the growth of microalgae at the sea surface. Lewis et al. (2020) challenge this notion with the first substantial observations of recent biomass buildup in the AO due to extra nitrogen fueled at the sea surface by various possible hydrodynamical processes.

The Arctic experiences the most extensive impacts of ongoing climate change, with modifications of the cryosphere being especially spectacular. The cascading effects on ecosystems are hard to diagnose and predict because we lack sufficient knowledge on this hardly accessible extreme environment. While Arctic land is broadly regarded as a cold desert, the Arctic Ocean hosts an oasis in its relatively warm waters. Arctic marine ecosystems harbor a rich and sometimes very abundant community of living organisms. From microbes to mammals and birds, these organisms thrive in the sea ice and ocean interior, as well as on the icepack itself and at the ocean bottom. Nearly all depend directly or indirectly on primary production (PP) of plant 
biomass by phytoplankton at the fundamental level of the food chain. In this most polar of oceans, phytoplankton must cope with two extraordinary constraints: a roller-coaster-like seasonal light cycle and a water column that is vertically organized into a mille-feuille. The underwater light regime is foremost controlled by celestial mechanics that give rise to the polar night and the midnight sun. It is further controlled by sea ice, which acts as a blind on top of the ocean before abruptly vanishing each summer over much of the AO. The vertical structure of the AO is characterized by a strong density gradient due to massive inputs of lightweight freshwater from rivers and ice melt, accumulating at surface. The resulting stratification limits vertical exchanges of solutes, and therefore the replenishment, in the surface layer, of the inorganic nutrients necessary to the growth of micro-algae. This phenomenon ultimately constrains the production of biomass at all levels of the food chain. Several recent studies put forward the idea that the magnitude of annual PP is primarily determined by the input of new nutrients (essentially nitrate) brought to the surface by vertical mixing (1), and that this constraint will become more severe because the AO is getting more strongly stratified due to increasing freshwater inputs (2). PP will decrease, despite the increase of underwater light resulting from sea ice shrinking. Light would mostly play a role in modulating seasonal variations in PP (1).

Lewis et al. (2020) used satellite observations of ocean color to determine the response of annual PP to climate change during the last two decades in the AO. Ocean color can be detected from space and analyzed to estimate the concentration of chlorophyll $a$ at sea surface, a proxy of phytoplankton biomass, and incident irradiance. When the atmosphere is cloud-free, these firstorder determinants of PP, together with sea-surface temperature, are monitored daily by several satellites over the entire World Ocean. Ocean color data have been uninterruptedly available 
since 1998. From the late 2000's on, several studies based on ocean color data have reported a significant increase in the annual PP of permanently or seasonally ice-free arctic waters (3-5). All have ascribed this increase primarily to the decrease in the extent of the icepack during summer and early fall, combined with the lengthening of the ice-free season. Open waters are exposed to much more sunlight then when sea ice, often covered by snow, is present. More light promotes more photosynthesis and biomass production by phytoplankton. How much of this increase results from new production that can be transferred to the food chain versus "useless" recycled production is however unclear. Lewis et al. now publish the longest Arctic PP time series. They show a progressive increase over time by $57 \%$, far exceeding previous estimates, and confirm the role of sea ice shrinking as a driver of PP, but only for the 1998-2008 period. Between 2009 and 2018, they show that the increase in PP is primarily driven by an increase in chlorophyll $a$ concentration, although they document significantly different regional trends. The standing stock of phytoplankton depends on the balance between gains due to growth, and losses largely due to grazing by zooplankton. But it also generally correlates with the concentration of nutrients. The key conclusion that can be drawn from Lewis et al.'s study is that the budget of inorganic nutrients may be augmenting in the AO rather than diminishing. Inputs of nutrients at the Pacific and Atlantic boundaries may be intensifying while the reduction in sea ice cover may expose the AO to stronger atmospheric forcings that promote more vertical mixing.

Will PP keep on increasing in the AO if sea ice keeps on shrinking? The rest of the story about the future of PP in AO ice-free waters will stem from longer time series and a better grasp of the physical phenomena that control nutrients including, as mentioned by Lewis et al., the Atlantification of the AO, wind-driven mixing during storms, and shelf-break upwellings. 
Satellites observations provide relatively long time series and a mean for exploring the AO at large scale. What we have learned from them on the AO is invaluable, as illustrated by Lewis et al.'s study. But they come with limitations as any observing technology: surface properties only; low spatial resolution; and low time resolution, especially for optical sensors limited by the presence of clouds that often only provide monthly binned data. The presence of sea ice, and the seasonal variations in underwater light make the surface AO more heterogenous and subject to steep transients in terms of physical, chemical and optical properties compared with other oceans. Scales relevant to PP span millimeters to ocean basin, and seconds to decades (see Figure 1). Importantly, satellites provide no observation under sea ice. Yet, what happens under the sea ice is equally important relative to PP. Indeed, intensive phytoplankton blooms have recently been observed under sea ice and are thought to be more common than previously anticipated (6). The ongoing thinning of sea ice, together with the increasing occurrence of melt ponds, that act as skylights at the surface of the sea ice during spring, may make them even more common (7).

How can we capture those important scales to PP and supplement ocean color remote sensing? Emerging sampling approaches include the use of autonomous sampling platforms (e.g. icetethered platforms, profiling floats, remotely-operated vehicles) that carry multiple sensors to explore the medium to large scales in ice-free and ice-covered waters, and the use of various satellite techniques (optical, microwave, active, passive) to characterize sea-ice optical properties and "guess" how PP may vary underneath at large to basin scales (8). Also, much remains to be done with regards to the small scales, for instance those relevant to micro-algae living in the 
inner interstices of sea ice. To fully address the current and future change in AO primary production and consequences on the marine trophic network, we face the challenge of developing new devices to explore the tiny, and an integrated observing system to capture and connect all relevant scales.

\section{References and Notes:}

1. J. E. Tremblay et al., Global and regional drivers of nutrient supply, primary production and $\mathrm{CO} 2$ drawdown in the changing Arctic Ocean. Progress in Oceanography 139, 171196 (2015).

2. P. Wassmann, M. Reigstad, Future Arctic Ocean Seasonal Ice Zones and Implications for Pelagic-Benthic Coupling. Oceanography 24, 220-231 (2011).

3. K. R. Arrigo, G. van Dijken, S. Pabi, Impact of a shrinking Arctic ice cover on marine primary production. Geophysical Research Letters 35, (2008).

4. K. R. Arrigo, G. L. van Dijken, Continued increases in Arctic Ocean primary production.

5 Progress in Oceanography 136, 60-70 (2015).

5. S. Bélanger, M. Babin, J.-É. Tremblay, Increasing cloudiness in Arctic damps the increase in phytoplankton primary production due to sea ice receding. Biogeosciences 10, (2013).

6. K. R. Arrigo et al., Massive Phytoplankton Blooms Under Arctic Sea Ice. Science 336, 1408-1408 (2012).

7. K. E. Lowry, G. L. van Dijken, K. R. Arrigo, Evidence of under-ice phytoplankton blooms in the Chukchi Sea from 1998 to 2012. Deep-Sea Research Part li-Topical Studies in Oceanography 105, 105-117 (2014).

8. G. C. Smith et al., Polar Ocean Observations: A Critical Gap in the Observing System and Its Effect on Environmental Predictions From Hours to a Season. Frontiers in Marine Science 6, (2019).

Acknowledgments: I am grateful to Martine Lizotte who revised advanced versions of the manuscript and provided valuable suggestions and comments.

Fig. 1. Rough schematic representation of the time and space scales spanned by various features, events and processes relevant to primary production in the Arctic Ocean. (1) Turbulent mixing. (2) Exchanges of nutrients and living organisms at the ice-water interface. (3) Sea ice inner interstices within which small living organisms thrive. (4) Horizontal variability in under-ice 
light due to snow, ridges and leads. (5) Vertical variability in light and nutrients in sea ice. (6) Sea ice thermodynamics. (7) Snow cover dynamics at small to medium scale (precipitation events, metamorphism, melt, horizontal distribution as affected by wind and sea ice roughness). (8) Ice micro-algae vertical and horizontal biomass variability at small to medium scale. (9) Marginal ice zone. (10) Fall transition at any given location where sea ice forms. (11) Spring transition in the marginal ice zone. (12) Storms. (13) Upwellings. (14) Phytoplankton vertical and horizontal biomass variability. (15) Large-scale variations due to sea ice dynamics, ice age and snow precipitations. (16) Decadal variations in atmospheric forcing due to the North Atlantic and Arctic Oscillations. (17) Bathymetry. 


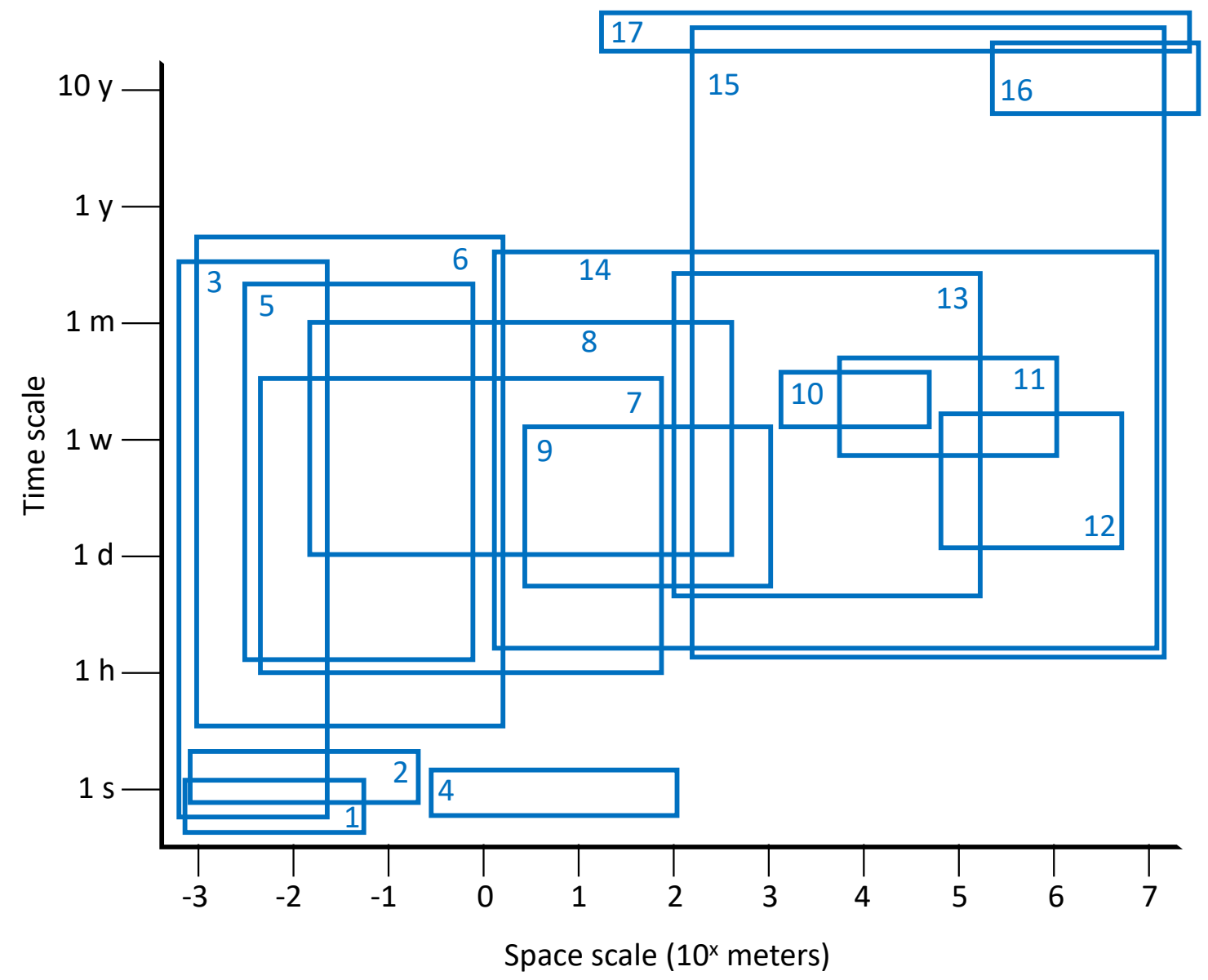

Figure 1. 


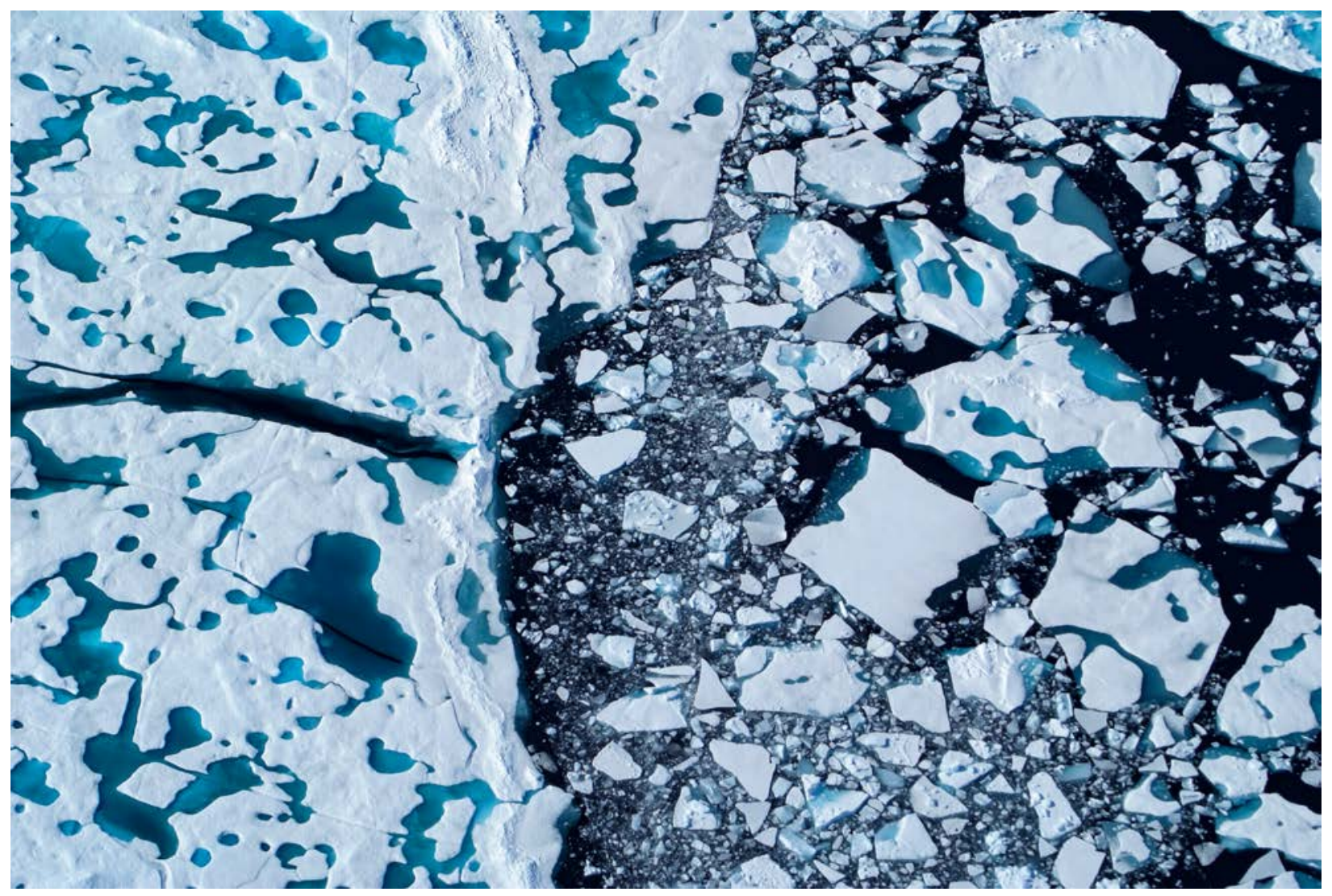

Picture 1. 


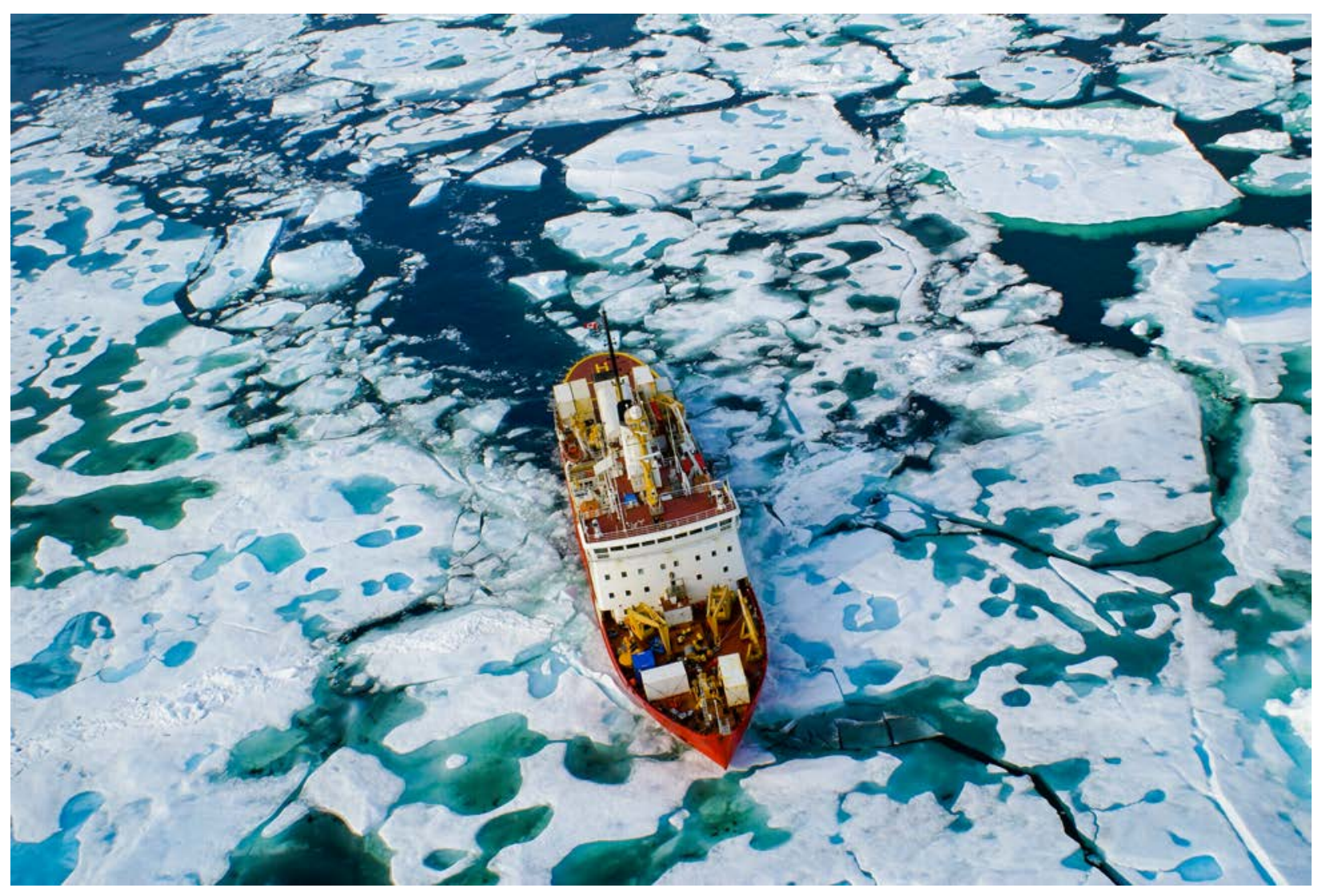

\section{Picture 2.}

